\title{
ARTISTIC AND AESTHETIC COMPETENCIES DEVELOPMENT: TRAINING TEACHERS USING DECORATIVE AND APPLIED ARTS
}

\author{
Oksana Marushchak \\ Vinnytsia Mykhailo Kotsiubynskyi State Pedagogical University, Ukraine \\ Tetiana Zuziak \\ Vinnytsia Mykhailo Kotsiubynskyi State Pedagogical University, Ukraine \\ Iryna Savchuk \\ Vinnytsia Mykhailo Kotsiubynskyi State Pedagogical University, Ukraine \\ Oleksii Rohotchenko \\ National Academy of Arts of Ukraine, Ukraine
}

\begin{abstract}
As Ukrainian national system of education is coming into being, aiming to promote development of personal competences on the basis of culture, art, and folk traditions of the Ukrainian people, introducing the spiritual heritage to the young generation, the problem of developing artistic and aesthetic competencies of the future teachers by means of decorative and applied arts becomes topical. The didactic value of the arts, as well as their limitless potential for competencies development are well recognized. This urged us to develop an artistic and aesthetic competencies training technique for the future teachers with the use of decorative and applied arts. The aim of the study is to test experimentally the effectiveness of this technique. The theoretical methods used are: analysis of psychological, pedagogical, methodological and specialized publications, of educational documentation; analysis, synthesis, abstraction, and systematization of data, comparative analysis of dissertations. Empirical methods are: questionnaire survey, observation, testing, independent peer review, analysis of students' practical results to determine criteria, indicators and levels of artistic and aesthetic competencies development; pedagogical experiment. Also used is the mathematical statistics method to analyze and determine effectiveness of the technique.
\end{abstract}

Keywords: artistic and aesthetic competence, students of pedagogical universities, contextual and technological support, decorative and applied arts, components of competence.

\section{Introduction}

One of the most important tasks for the Ukrainian state is to create a national education system that will foster the development of personal competences based on the culture and art of the Ukrainian people, on folk traditions, introducing the spiritual heritage to the young generation (Marushchak, Kashuba, \& Magdych, 2018). The problem of a scientifically grounded system of professional training 
of the future teachers in the field of arts and crafts (AnC) is of great importance, especially taking into account contemporary global and national tendencies in the development of pedagogical education, prospective spiritual and creative aesthetic orientations. Within this context, artistic and aesthetic competencies are the key components of the future teachers' professionalism. Despite many developments on the problem in theoretical studies, the pedagogical, contentrelated and methodical aspects of building artistic and aesthetic competencies of future teachers by means of AnC remain insufficiently investigated.

The purpose of the study is to test experimentally the effectiveness of technique that develops the artistic and aesthetic competencies by means of decorative and applied arts in the students of pedagogical universities. The objectives of the study are to justify the criteria, to determine the indicators and identify the levels of artistic and aesthetic competencies; to experimentally verify the effectiveness of content and technological support for the development of artistic and aesthetic competencies in students by the means of AnC.

\section{Research methodological foundations and methods}

The axiological, multicultural, participatory, poly-artistic approaches are the methodological basis for the development of artistic and aesthetic competencies in the students of pedagogical universities. To achieve the objectives of the study, a pedagogical experiment was set, the ascertaining stage of which included 349 students the specialties (of specialties 014 Secondary education (Labor education and technology), 015 Professional education (Service sector), according to Ukrainian system) of the Vinnytsia Mykhailo Kotsiubynskyi State Pedagogical University, National Pedagogical Dragomanov University, and Pavlo Tychyna Uman State Pedagogical University. The experiment sought to determine the state and levels of the artistic and aesthetic competencies development. A set of research methods was used, i.e. original questionnaire survey by the authors to evaluate all mentioned criteria, N. Samsonova's adapted method of "Unfinished sentence” that tests the cognitive criterion (Vaynola \& Khlyestova, 2010); M. Rokych's method "Value orientations" to evaluate motivation and values (Darvysh, 2003); the narrative methods and methods of overt observation, of ranking, of independent expert evaluations to assess activity-based criterion and practical use.

At the formative stage of the study, the objective of which was to test the effectiveness of the proposed technique of building artistic and aesthetic competencies in future teachers by means of AnC, the control (CG) and experimental (EG) groups were determined, which numbered 147 and 172 students accordingly, with almost the same level of artistic and aesthetic competencies. 
In order to substantiate development of artistic and aesthetic competencies, the methods of analysis, synthesis, abstraction, systematization of theoretical data were applied; to determine the criteria, indicators and levels of the competencies, the methods of questioning, observation, testing, independent expert assessments, analysis of the results of students' practical activity were applied. To detect statistically significant difference in changes in the levels of formation of indicators of artistic and aesthetic competencies in the control and experimental groups - that is, the effectiveness of the proposed technique, rather than the influence of random factors - the single-factor variance analysis method by P. Volovyk was used.

\section{Results and discussion}

The concept of artistic and aesthetic competencies is extremely broad and encompasses the motivational, perceptual, cognitive, creative, activity and reflexive spheres of personality structure. In our study (Zuziak \& Marushchak, 2019), we define artistic and aesthetic competencies as a professional-personal multidimensional phenomenon that has a metastructure and is characterized by the ability to create original works of decorative and applied arts, by willingness to assimilate the achievements of the global and national folk art, folk culture and creativity, artistic taste, artistic knowledge and value judgments.

The artistic competence of a future teacher is a formation within his personality, a single, integral structure that cannot exist without the components that comprise it. Among the main components we distinguish: cognitive, motivation \& value, activity-based and practical use.

The cognitive component outlines the awareness of the individual about the values of the native ethnos, embodied in the folk traditions of decorative and applied arts. It implies having a complex of artistic and aesthetic knowledge; the perception of decorative art as a social phenomenon and as a constantly evolving system; awareness of the AnC's connection with the thinking, culture and social development of people. The cognitive component is closely related to a specific subjective activity of the individual. Artistic knowledge influences the development of the ability to distinguish socially significant aspects in decorative and applied arts, to analyze the details of content and form of these works.

The motivational and value component implies the presence of motives, values, goals, and need for vocational training, improvement, self-education, selfdevelopment. The latter actualize the need to build artistic and aesthetic competencies by means of AnC and stimulate artistic and creative expression of personality in professional activity, provide understanding of arts and crafts within the context of cultural development of society, reflect the motivation of the individual for development, conservation and multiplication of the traditions of 
Marushchak et al., 2020. Artistic and Aesthetic Competencies Development: Training Teachers Using Decorative and Applied Arts

certain ethnic group. It assumes an interest in professional activity that characterizes a person's need for knowledge, for mastering effective ways of organizing professional activity; it includes motives for pedagogical activity, focuses on knowledge transfer and development of students' personality. According to psychologist S. Kaverin (Kaverin, 1987), the need for creative activity is a higher need, which indicates a high degree of personality development. According to him, the main motives of creativity are curiosity, personal interest, and higher social motives.

Values reflect the core of basic human motivations. Attitude towards national culture, towards the age-old traditions of the Ukrainian people that are based on values, and value awareness of a teacher in the field of arts and crafts permeates the whole practical basis of his pedagogical activity. One of the most important qualities of a future teacher in the field of arts and crafts is the ability to correctly determine the aesthetic values of the works of the art in question and reason his attitude to the students. One should teach students to perceive, evaluate and understand the values and meanings of AnC works.

The activity-based and practical use component reflects the ability of an individual to know and preserve the folk traditions of certain ethnic group, as well as the activities and practical reality within which they are reproduced and creatively transferred on the basis of acquired knowledge and skills. This component allows the use of existing professional knowledge, skills and competences to accomplish the objectives of professional activity. It is closely related to the development of practical skills in arts and crafts, which involve mastering all types of artistic and aesthetic activities (art and applied graphics, drawing, painting, ethnological sculpture, decorative plastics, decorative and applied works) that can be defined as spiritual and practical activity. The organizational and pedagogical basis of the activity-based and practical use component are techniques and methodology, which broaden and deepen the professional consciousness, and help choose the forms of communication in educational systems between a teacher, a product of AnC, and a student.

Theoretical analysis of the criteria factors of development of artistic and aesthetic competencies in the students of pedagogical universities by means of decorative and applied arts allowed us to characterize the levels of development of these competencies, namely, low, medium, sufficient and high.

Assessment of the level of development of artistic and aesthetic competencies by means of AnC was performed in accordance with the predeveloped indicators and was reduced to a single coefficient scale. In order to optimize the calculations, we evaluated each structural component individually, and then calculated the arithmetic mean, thus adjusting the coefficient scale to four levels of students' artistic and aesthetic competencies' indicators. We subsequently used the following distribution scales: 1-1.7 points - low level; 
1.7-2.7 points - average level; 2.8-3.4 points - sufficient level; 3.5-4 points - high level. The experiment involved 349 students of pedagogical universities of the specialties 014 Secondary education (Labor education and technology) and 015 Professional education (Service sector). According to the criteria, during the ascertainment experiment we identified the level of structural components of artistic and aesthetic competence (Table 1).

Table 1 The level of development of artistic and aesthetic competencies' components by means of decorative and applied art

\begin{tabular}{|c|c|c|c|c|c|c|c|c|}
\hline $\begin{array}{c}\text { Structural components of artistic } \\
\text { and aesthetic competence }\end{array}$ & \multicolumn{2}{|c|}{ High level } & \multicolumn{2}{c|}{$\begin{array}{c}\text { Sufficient } \\
\text { level }\end{array}$} & \multicolumn{2}{c|}{$\begin{array}{c}\text { Medium } \\
\text { level }\end{array}$} & \multicolumn{2}{c|}{ Low level } \\
\cline { 2 - 10 } & abs. & $\%$ & abs. & $\%$ & abs. & $\%$ & abs. & $\%$ \\
\hline Cognitive & 25 & 7.2 & 79 & 22.6 & 138 & 39.5 & 107 & 30.6 \\
\hline Motivational and value & 9 & 2.6 & 113 & 32.4 & 94 & 26.9 & 133 & 38.1 \\
\hline Activity-based and practical use & 70 & 20.1 & 124 & 35.5 & 115 & 32.9 & 40 & 11.5 \\
\hline
\end{tabular}

The table 1 illustrates that $7.2 \%$ of students have a high level of cognitive component of artistic and aesthetic competencies. They show a high level and deep professional theoretical knowledge of the arts and crafts, of cultural outlook, of awareness regarding the use of techniques and technologies for performing various types of professional tasks (both as executors and personally set ones); the development of artistic and pedagogical thinking, which is reflected in the combination of visual and theoretical thinking; developed perceptual, research, innovative skills and system of psychological and pedagogical knowledge in the course of organizing artistic and creative activity.

Only $2.6 \%$ of students show a high level of motivation and values. This component is characterized by the conscious choice of profession, understanding of its importance and moral responsibility for the results of professional activity, need for constant professional growth, creative development and self-education, desire to embrace the cultural heritage, to cherish the cultural values; the artistic and aesthetic values are treated as personal values, there is a strong inclination to preserve and disseminate artistic and aesthetic values, a positive motivation for artistic and aesthetic activity, interest in the AnC in the context of cultural development of society, etc.

$20.1 \%$ of students show high level of activity-based and practical component of artistic and aesthetic competence. High level of this component corresponds to the ability to carry out artistic and creative activity, to create a product of artistic and aesthetic activity, to transfer ideas of folk art into practical professional activity; to the ability to interpret the works of folk art independently.

$22.6 \%, 32.4 \%$ and $35.5 \%$ respectively showed a sufficient level of all the three components of artistic and aesthetic competencies. Other students have 
Marushchak et al., 2020. Artistic and Aesthetic Competencies Development: Training Teachers Using Decorative and Applied Arts

medium and low levels. Thus, it can be concluded that regarding the three structural components students are most active in activity-based and practical use. Other components - cognitive and motivational \& value - are at a low level, which could explained by the lack of targeted training.

Only $55.6 \%$ of students have high and sufficient levels of practical component of artistic and aesthetic competence, which proves the overall low level of future teachers' own techniques of personal expression and selfdevelopment in the field of artistic and aesthetic activity by means of AnC. This also reflects readiness for professional growth and substantiates the need for developing artistic and aesthetic competencies in future teachers by means of decorative and applied arts.

Table 2 shows the general picture of students' high, sufficient, medium and low levels of artistic and aesthetic competencies.

Table 2 The level of development of artistic and aesthetic competencies by means of decorative and applied arts

\begin{tabular}{|c|c|c|}
\hline Levels of artistic and aesthetic competence & Quantity of students & $\%$ \\
\hline High & 16 & 4.6 \\
\hline Sufficient & 66 & 18.9 \\
\hline Medium & 128 & 36.7 \\
\hline Low & 139 & 39.8 \\
\hline
\end{tabular}

It is clear from the table 2 that only $23.5 \%$ of students are ready to carry out art and crafts pedagogical activities at high (4.6\%) and sufficient (18.9\%) levels. The rest of the students have medium (36.7\%) and low (39.8\%) levels of artistic and aesthetic competencies by means of AnC, which does not meet the contemporary requirements for highly qualified specialists, capable of performing art and pedagogical activities, aimed to preserve the traditions of folk decorative art and based on prospective spiritual and creative aesthetic orientations. Thus, the obtained quantitative results of the ascertaining experiment confirm our conclusions about the insufficient level of development of artistic and aesthetic competencies in future teachers by means of AnC. Therefore, the tasks of the experimental work regarding development of teaching technique and materials need to be further specified.

At the formative stage of the study, the structure of CG and EG was determined, consisting of 147 students and 172 students, respectively, who had almost the same level of artistic and aesthetic competencies. At the same time, high and sufficient levels of competencies the experimental group were even lower than in the control group, which is reflected in Table 3. 
Proceedings of the International Scientific Conference. Volume V, May $22^{\text {th }}-23^{\text {th }}$, 2020. 719-728

Table 3 The level of development of artistic and aesthetic competencies by means of AnC in experimental and control groups (before experiment)

\begin{tabular}{|c|c|c|c|c|}
\hline \multirow{2}{*}{$\begin{array}{c}\text { Levels of development of artistic } \\
\text { and aesthetic competencies }\end{array}$} & \multicolumn{2}{|c|}{ CG } & \multicolumn{2}{c|}{ EG } \\
\cline { 2 - 5 } & $\begin{array}{c}\text { Quantity of } \\
\text { students }\end{array}$ & $\%$ & $\begin{array}{c}\text { Quantity of } \\
\text { students }\end{array}$ & $\%$ \\
\hline high & 8 & 5.4 & 6 & 3.5 \\
\hline sufficient & 28 & 19.1 & 31 & 18 \\
\hline medium & 52 & 35.4 & 64 & 37.2 \\
\hline low & 59 & 40.1 & 71 & 41.3 \\
\hline
\end{tabular}

Recognition of didactic (cognitive, practical, developmental, artistic and cultural) value of decorative and applied arts, as well as its limitless potential for the development of artistic and aesthetic competencies, led to the development of technique of this process, providing value-orientation, information-cognitive, interpretative, reflexive, personal-developmental stages.

The value-orientation stage aims to solve the following tasks: development of students' emotional sphere through understanding of the emotional content of AnC works; development of a positive attitude towards oneself and chosen professional activity; creation of conditions for the emergence of interest in art, in its evaluation in accordance with the ideas of the aesthetic ideal, the creation of an artwork by means of decorative and applied arts; development of desire for the personal growth on the basis of self-knowledge and self-awareness as an artist and a teacher.

Development of artistic and aesthetic knowledge, skills, experience, aesthetic orientation, based on knowledge, student's experience and mastery of artistic and aesthetic means is carried out most fully during the informationcognitive stage of the proposed technique.

The interpretative stage involves the students' realization of their activity as a process of active research, mastering of knowledge, acquisition of practical and creative experience through motivated and purposeful solving of pedagogical tasks. In other words, personal and professional development of a future teacher should be conducted in unity, which is determined by the features of artistic and pedagogical activity and artistic and aesthetic education during the process of communication with art.

At the reflexive stage, we use a portfolio of students' educational and creative achievements, the creation of which allows to combine mastery of artistic and aesthetic knowledge, skills, experience with AnC and direct involvement in practical artistic and aesthetic activities. This promotes the generation of aesthetic ideas, helps to enrich, find ways and techniques of artistic expression; to reflect the dynamics of students' development, involves them in constant communication with art and engages in artistic and creative activities. It also serves as a diagnostic 
tool for independent cognitive and artistic and practical activity; a means of selfesteem, which includes the ability to analyze the course and results of their own practical (professional, creative, research, artistic and aesthetic) activity, to objectively evaluate themselves, their level of artistic skills (self-control, selfanalysis, self-esteem).

At the personal-developmental stage, there is a connection between universal knowledge and forming one's own image of the world. At the same time, through artistic and aesthetic activity, the individual establishes some connection with the outside world, the aesthetic relations with reality, while changing himself, his abilities and inner spiritual world at the same time. This process is based on the general provisions of person-oriented learning, which involves cooperation, partnership of a teacher and a student, self-development of the agents of the educational process. The personality of a future specialist is formed during the process of modeling the situations of real professional activity, during creating challenging situations. It should be borne in mind that the ability of the individual to self-communication while embracing the traditions of arts and crafts, the ability to engage in artistic dialogue with his and other ethnic groups on the basis of tolerance, understanding, mutual respect contribute to personal development and introduction to global spiritual heritage.

At the value-orientation stage, the leading forms of competencies development by means of AnC were: conversations on culture (characteristics of historical origins of certain art techniques, algorithms of creating cultural masterpieces; themed art history conversations; biographical conversations, which detailed the biography and artistic style of the masters of the AnC), creative discussions and debates, video lectures, student exhibitions, workshops. We have chosen the methods of awareness development, information-searching methods and methods of folk pedagogy.

At the informative-cognitive stage we applied consciousness-forming methods and information-searching methods using lectures, mini-lectures, interactive reports, cultural talks, museum hours and study tours.

At the interpretative and personal-developmental stages of the technique we have chosen methods of organization of activity, interactive methods and methods of creation of artistic context. Priority forms of translating the artistic images into practical activity and the ability to create a product of artistic and aesthetic activity were the development of a project and conducting themed workshops, which allowed to thoroughly approach the study of types and techniques of AnC.

To determine the level of development of artistic and aesthetic competencies by means of AnC according to various criteria, at the formative stage of the study we used observation of students' work, surveys, analysis of completed works and their portfolios. The dynamics of the level of competencies in students of experimental and control groups, determined by the calculation of the arithmetic 
mean of all three structural components, is presented in Table 4.

Table 4 Dynamics of the level of development of artistic and aesthetic competencies by means of AnC in the students of experimental and control groups

\begin{tabular}{|c|c|c|c|c|c|c|c|c|}
\hline \multirow{3}{*}{$\begin{array}{c}\text { Levels of } \\
\text { development } \\
\text { of artistic and } \\
\text { aesthetic } \\
\text { competencies }\end{array}$} & \multicolumn{4}{|c|}{ Before experiment } & \multicolumn{4}{|c|}{ After experiment } \\
\hline & \multicolumn{2}{|c|}{ CG } & \multicolumn{2}{|l|}{ EG } & \multicolumn{2}{|c|}{ CG } & \multicolumn{2}{|c|}{ EG } \\
\hline & $\begin{array}{r}\text { Students' } \\
\text { quantity }\end{array}$ & $\%$ & $\begin{array}{l}\text { Students' } \\
\text { quantity }\end{array}$ & $\%$ & $\begin{array}{c}\text { Students' } \\
\text { quantity }\end{array}$ & $\%$ & $\begin{array}{l}\text { Students' } \\
\text { quantity }\end{array}$ & $\%$ \\
\hline High & 8 & 5.4 & 6 & 3.5 & 12 & 8.2 & 37 & 21.5 \\
\hline sufficient & 28 & 19.1 & 31 & 18 & 31 & 21.1 & 52 & 30.2 \\
\hline medium & 52 & 35.4 & 64 & 37.2 & 55 & 37.4 & 61 & 35.5 \\
\hline low & 59 & 40.1 & 71 & 41.3 & 49 & 33.3 & 22 & 12.8 \\
\hline Total: & 147 & 100 & 172 & 100 & 147 & 100 & 172 & 100 \\
\hline
\end{tabular}

Therefore, we can conclude that the overall level of development of artistic and aesthetic competencies of future teachers by means of AnC according to the proposed technique has changed qualitatively. The experimental groups show the greater dynamics of the mentioned competencies. The number of students in the experimental groups who developed a high level of artistic and aesthetic competence increased by $18 \%$ (in the control groups it was $2.8 \%$ ). In the experimental groups, the number of students who reached the sufficient level of competencies increased by $12.2 \%$, compared to $2.0 \%$ of the students in the control groups. The number of students with an average level of artistic and aesthetic competencies decreased by $1.7 \%$; $35.5 \%$ of students showed this level of competencies in the end. Although the total number of students with average level of competencies development has hardly changed, there were qualitative alterations within this group. The control groups at this level also experienced changes, though not significant, with the number of students with an average level of artistic and aesthetic competencies increasing by $2 \%$. At the same time, the number of students of the experimental groups with a low level of competencies reduced to $28.5 \%$, compared to $6.8 \%$ of the students of the control groups.

In order to check the effectiveness of the proposed technique, the effectiveness of content and technological support of the artistic and aesthetic competencies development in future teachers by means of AnC and to identify a statistically significant difference in changes in the levels of formation of its indicators, we used the statistical method of one-factor analysis by P. Volovyk (Volovyk, 1976). The statistically significant results of the formative experiment with the probability of $\mathrm{P}=0.95$ give grounds to state that that the studied technique has a significant impact on the formation of artistic and aesthetic competencies of the students by means of decorative and applied arts. In addition, 
Marushchak et al., 2020. Artistic and Aesthetic Competencies Development: Training Teachers Using Decorative and Applied Arts

the process of building the considered competence according to the technique in the experimental groups was more effective than in the control groups.

\section{Conclusions}

Qualitative analysis of experimental learning and statistical significance confirm the differences between the level of artistic and aesthetic competence in the experimental and control groups of students. In the experimental groups, the level of artistic and aesthetic competence development has increased significantly comparing to the control ones, which proves the effectiveness of the proposed technique of building the artistic and aesthetic competencies by means of AnC within the students of pedagogical university.

\section{References}

Darvysh, O. (2003). Vozrastnaia psikhologiia [Age Phychology]. Moscow: VLADOS-PRESS. (In Russian)

Kaverin, S. (1987). O psikhologicheskoy klassifikatsii potrebnostey [On the Phychological Classification of Needs]. Voprosy psikhologii [Issues of Psychology], 5, 121-129. (In Russian)

Marushchak, O., Kashuba, A., \& Mahdych, Ya. (2018). Metodychni aspekty etnokulturnoho vykhovannia uchniv starshoi shkoly zasobamy DUM [Methodological Aspects of Ethnical and Cultural Education of the High School Pupils with the Use of Decorative and Applied Arts]. Aktualni problemy pidhotovky vchytelia trudovoho navchannia ta tekhnolohii serednoi shkoly: teoriia, dosvid, problemy [Topical Issues of a Handicraft Teacher's Training and Educational Techniques of the Middle School], 1, 228-232. (In Ukrainian)

Vaynola, R., \& Khlyestova, S. (2010). Deontologichna kultura [Deonthological Culture]. Vinnytsia: DKF. (In Ukrainian)

Volovyk, P. (1976). Zastosuvannia dyspersiinoho analizu v pedahohichnykh doslidzhenniakh [Using Analysis of Variance in Pedagogical Research]. Radianska shkola [Soviet School], 6, 29-37. (In Ukrainian)

Zuziak, T., \& Marushchak, O. (2019). Formation of artistic-aesthetic competence means of decorative and consumer art: content and structure of phenomenon. In A. Jankovska (Ed.), Development of Modern Science: The Experience of European Countries and Prospects for Ukraine (pp. 17-40). Riga, Latvia: Baltija Publishing.

DOI: https://doi.org/10.30525/978-9934-571-78-7_18. 